\title{
MOLECULAR BASES OF TROPISM IN THE PUR46 CLUSTER OF TRANSMISSIBLE GASTROENTERITIS CORONAVIRUSES
}

\author{
M. L. Ballesteros, C. M. Sánchez, J. Martín-Caballero, and L. Enjuanes \\ Department of Molecular and Cellular Biology \\ Centro Nacional de Biotecnología, CSIC \\ Campus Univesidad Autónoma \\ Cantoblanco, 28049 Madrid, Spain
}

\begin{abstract}
Transmissible gastroenteritis coronavirus (TGEV) infects both, the enteric and the respiratory tract of swine. S protein, that is recognized by the cellular receptor, has been proposed that plays an essential role in controlling the dominant tropism. The genetic relationship of $\mathrm{S}$ gene from different enteric strains and non-enteropathogenic porcine respiratory coronaviruses (PRCVs) was determined. A correlation between tropism and the genetic structure of the $\mathrm{S}$ gene was established. PRCVs, derived from enteric isolates have a large deletion at the $\mathrm{N}$-terminus of the $\mathrm{S}$ protein. Interestingly, two respiratory isolates, attenuated Purdue type virus (PTV-ATT) and Toyama (TOY 56) have a full-length S gene. PTV-ATT has two specific amino acid differences with the $S$ protein of the enteric viruses. One is located around position 219 , within the deleted area, suggesting that alterations around this amino acid may result in the loss of enteric tropism.

To study the role of different genes in tropism, a cluster of viruses closely related to PUR46 strain was analyzed. All of them have been originated by accumulating point mutations from a common, virulent isolate which infected the enteric tract. During their evolution these viruses have lost, virulence first, and then, enteric tropism. Sequencing analysis proved that enteric tropism could be lost without changes in ORFs 3a, 3b, 4, 6, and 7, and in $3^{\prime}$-end untranslated regions ( $3^{\prime}-\mathrm{UTR}$ ). To study the role of the $\mathrm{S}$ protein in tropism recombinants were obtained between an enteric and a respiratory virus of this cluster. Analysis of the recombinants supported the hypothesis on the role in tropism of S protein domain around position 219.
\end{abstract}

\section{INTRODUCTION}

TGEV, infects both, the enteric and the respiratory tract of swine. TGEV must attach to host cells through the $\mathrm{S}$ glycoprotein, since monoclonal antibodies (MAbs) specific for 
the S glycoprotein, but not MAbs specific for the $\mathrm{N}$ or M proteins inhibit the binding of the virus to ST cells ${ }^{16}$. Then it should be expected that $S$ protein plays an important role in the control of dominant tropism. In fact, there are data from different laboratories establishing a correlation between the S protein gene structure and tropism. PRCVs have been originated, independently, in Europe ${ }^{12,3}$ and in North America ${ }^{18}$, from enteric isolates ${ }^{14}$. PRCVs show a large deletion at the $\mathrm{N}$-terminus of the $\mathrm{S}$ protein, including the antigenic sites $\mathrm{C}$ and $\mathrm{B}^{14}$. Interestingly, there are two respiratory isolates, PTV-ATT and TOY56, with a full-length S gene, without deletion. The $\mathrm{S}$ genes of these viruses have been sequenced and compared to $\mathrm{S}$ genes from the enteric isolates. In PTV-ATT, only two nucleotide differences, leading to two specific amino acid changes were found. One was located around amino acid 219, within the deleted area, while the other was outside ${ }^{14}$. Our laboratory has proposed that alterations around position 219 may be responsible for the loss of enteric tropism in these viruses.

However, it cannot be excluded that other genes could be involved in tropism. ORF3 has accumulated a large number of nucleotide changes among enteric isolates and PRCVs, including both, insertions and deletions ${ }^{13,2,17,9}$. Most important, ORF3a is expressed in the enteric isolates but not in PRCVs, due to a nucleotide change in the ORF3a consensus region. In contrast, in the nearest genes $3 \mathrm{~b}$ and 4 , there are no specific mutations between enteric viruses and PRCVs. To analyze the role of different genes in tropism a cluster of viruses closely related to the PUR46 strain was studied.

\section{MATERIALS AND METHODS}

\section{Cells and Viruses}

All viruses were grown on swine testis (ST) cells ${ }^{11}$. The characteristics of TGEV strains: PUR46-SW11 ${ }^{6}$, provided to us by M. Pensaert and PUR46 ${ }^{1,15}{ }^{14}$, have been described. PTV-ATT, a Purdue type virus, was previously named NEB72. Due to the relationship between NEB72 and other TGEVs in the epidemiological tree developed ${ }^{14}$ and to its sequence homology with the PUR46 isolate we have renamed this virus strain. Both, PTV-ATT and a temperature sensitive mutant, PTV-ATTts, derived from it, were kindly provided by M. Welter and L. Welter. PTVtsdmar was derived from PTV-ATTts. This virus is temperature sensitive and has modified the antigenic subsites $\mathrm{Aa}$ and $\mathrm{Ab}$ of the $\mathrm{S}$ protein.

Recombinants were obtained by coinfection with two parental strains: respiratory PTVtsdmar and enteric PUR46. The progeny was selected using MAbs and restrictive temperature.

\section{RNA Analysis}

RNA was sequenced by different procedures: directly from viral $\mathrm{RNA}^{5}$ or deriving cDNA fragments by RT-PCR; cDNA fragments were sequenced using fmol system (Promega) or cloned into pBluescript to be sequenced using the Sequenase kit (USB).

To analyze a point mutation in nucleotide 655 of S gene, cDNA fragments containing the mutated position were RT-PCR derived and their susceptibility to BsmAI restriction endonuclease enzyme studied.

\section{Virus Tropism}

Tropism was studied in conventional, non-colostrum-deprived, newborn mini-swine. Piglets were orally inoculated by stomach tube and slaughtered at 24,48 , and 72 hours 
post-infection. Animal room was kept at $22^{\circ} \mathrm{C}$. Lungs and small intestine were collected and homogenized in PBS. A sample was separated and virus titer determined by plaque-assay ${ }^{7}$.

\section{RESULTS}

To study the role of different genes in tropism a cluster of closely related viruses was studied (Fig. 1). All of them have been originated, by accumulating point mutations, from a common and virulent, ancestor PUR46-SW11 that infects the enteric tract. All these isolates have, as a trade mark, a small deletion of six nucleotides in the $\mathrm{S}$ gene. These viruses have evolved, losing their virulence (PUR46) and their enteric tropism (PTV-ATT and PTVtsdmar).

ORFs 2, 3a, 3b, 4, 6, and 7 and the 3'-UTR were sequenced in PUR46, PTV-ATT and PTVtsdmar. Sequence comparison of the genomes of the enteric isolate PUR46 and its respiratory derivative PTV-ATT showed that no nucleotide was changed in 3 '-UTR and in ORFs 7, 6, and 4. In ORFs $3 a$ and $3 b$ only two nucleotide differences were found. One was located in the non-coding region between the two genes, and the other in ORF3b. Viruses of this cluster do not express ORF3b because they have a point mutation in the consensus region. These data show that, in contrast to what has been previously suggested ${ }^{17}$, enteric tropism may be lost without changes in ORF3a.

Between the S genes of PUR46 and PTV-ATT, only two nucleotides have mutated leading to two specific amino acid changes. One was nucleotide 655 , located within the deleted area of the PRCVs. The other was nucleotide 2098. To determine if these positions were involved in tropism, ST cells were coinfected with the enteric PUR46 and the respiratory PTVtsdmar. Recombinants were obtained having either, both or only one nucleotide changed. The recombinant isolation frequency was estimated to be very low

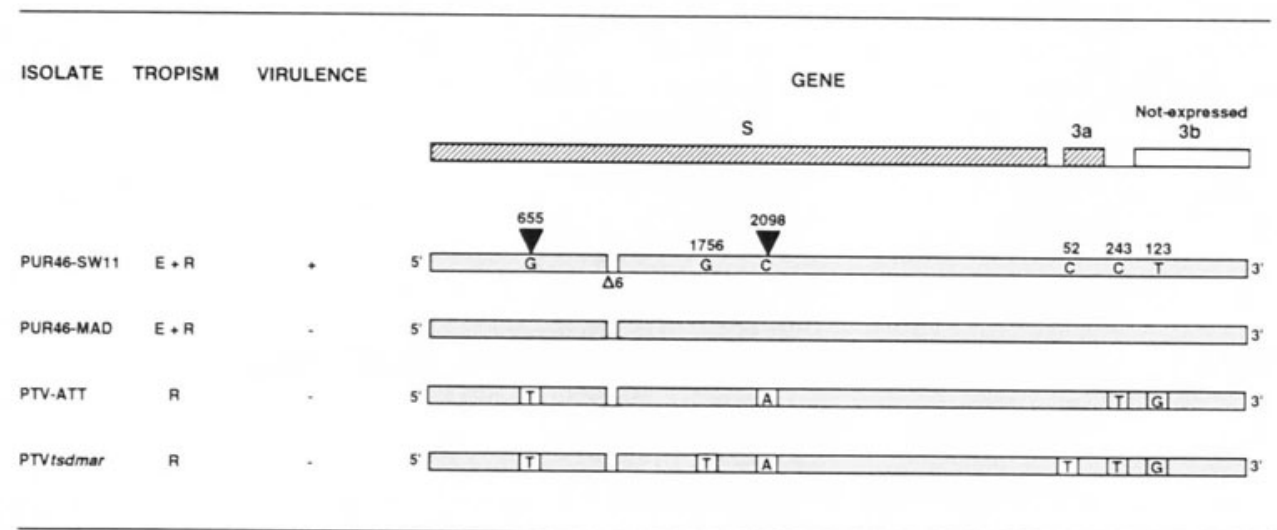

CHANGE OF NUCLEOTIDE IMPL YING CHANGE IN AMINO ACID

CHANGE OF NUCLEOTIDE WITH NO CHANGE IN AMINO ACID

Figure 1. Summary of nucleotide changes in genes S, 3a, and 3b of PUR46-related viruses. Genes 2, 3a, and $3 \mathrm{~b}$ were sequenced and compared in the cluster of PUR46-related viruses, including PUR46-SW11, PUR46MAD, PTV-ATT, and PTVtsdmar isolates. Bars represent the studied genes. White and dotted squares indicate the position of nucleotide causing a change or no modification, respectively, in the amino acid sequence. Letters represent nucleotides. Numbers above these letters indicate the location of nucleotides referring to the ATG of each gene. $\Delta 6$ indicates a deletion of 6 nucleotides, in relation to the sequence of the MIL65 strain. Virus tropism is indicated with $\mathrm{E}+\mathrm{R}$ when virus infects both, the enteric and the respiratory tract, and with $\mathrm{R}$ when virus only infects the respiratory tract. Virulence is designed by + if virus kills piglets or by - when not, in the assay conditions described in Materials and Methods. 
Table 1. Phenotypic characterization of potential recombinants between enteric PUR46 and respiratory PTVtsdmar

\begin{tabular}{lcccc}
\hline Recombinant group & $\begin{array}{c}\text { Neutralization index } \\
\text { (MAbs) }\end{array}$ & $\begin{array}{c}\text { Inactivation index } \\
\text { (temperature) }\end{array}$ & Number of clones & $\%$ \\
\hline PUR46wt & $3.7 \pm 0.3$ & $0.5 \pm 0.3$ & 0 & - \\
PTVtsdmar & $0.5 \pm 0.3$ & $3.0 \pm 0.2$ & 3 & 9.7 \\
Group 1 & $3.7 \pm 0.3$ & $3.0 \pm 0.2$ & 0 & - \\
Group 2 & $0.5 \pm 0.3$ & $0.5 \pm 0.3$ & 15 & 48.4 \\
Group 3 & $1.2>\mathrm{NI}>0.5$ & $2.4>\mathrm{II}>0.5$ & 13 & 41.9 \\
\hline
\end{tabular}

$\left(<1.0 \times 10^{-6}\right)$ in this cluster of viruses. The progeny phenotype was determined (Table 1). Recombinants were classified in three groups according to their resistance to MAbs and restrictive temperature. Selection was performed against group 1 (sensitive to both, neutralization by MAbs and inactivation at restrictive temperature) and, in fact, no virus with this phenotype was isolated. Group 3 contained viruses having an intermediate phenotype between the two parental strains. Almost $50 \%$ of the progeny showed the expected recombinant phenotype (group 2), resistant to both, neutralization by MAbs and inactivation at restrictive temperature.

To genotypically characterize group 2 recombinants two nucleotide differences between the $\mathrm{S}$ genes of the two parental viruses were used. According to the position of the crossing-over, recombinants were split up into two groups (Fig. 2). Group 2A had recombined in the $\mathrm{S}$ gene, between the two nucleotide differences, taking position 655 from the enteric parental (PUR46), while nucleotide 2098 from the respiratory one (PTVtsdmar). The mutation responsible for the lack of antigenic subsites $\mathrm{Aa}$ and $\mathrm{Ab}$ had been previously mapped at nucleotide 1756 of ORF2. The crossing-over of this group of recombinants was located between nucleotides 655 and 1756. A high number of the analyzed recombinants, more than $40 \%$, showed this structure. Group $2 \mathrm{~B}$ had recombine $5^{\prime}$ upstream of the $\mathrm{S}$ gene, although the exact position of the crossing-over has not yet been mapped. Group 2B

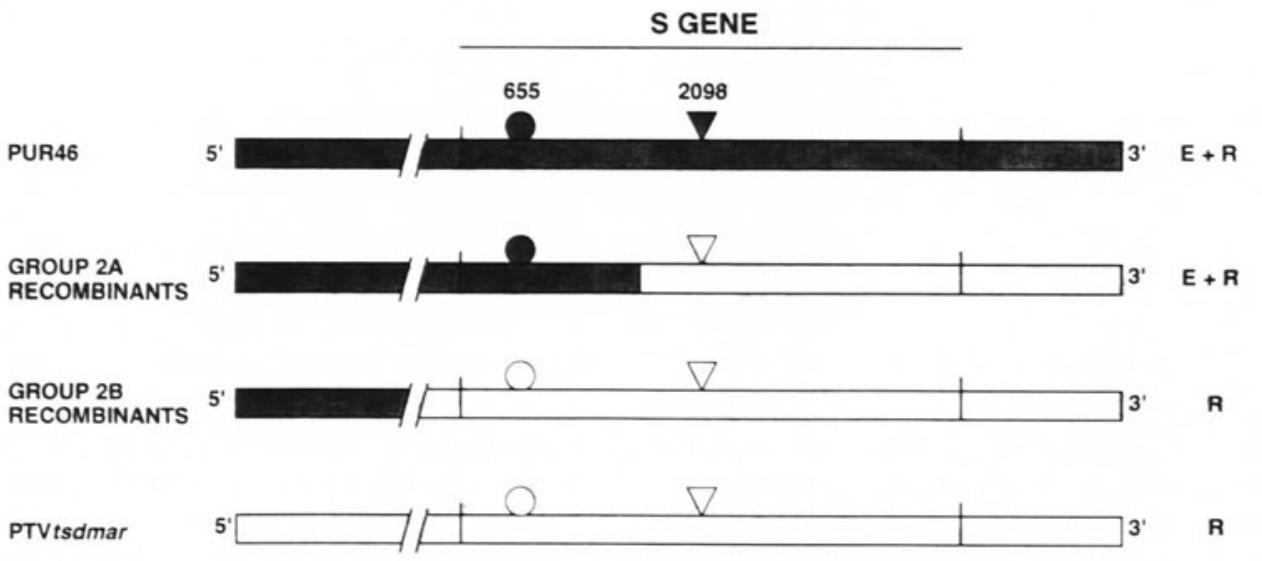

Figure 2. Genetic structure of the recombinants obtained by crossing the enteric PUR46 and the respiratory PTVtsdmar. Full and empty bars indicate sequences coming from PUR46 or PTVtsdmar, respectively. The nucleotide difference of position 655 is marked by a circle and the difference at position 2098 by a triangle. Two Kb of ORF1b 3'-end were sequenced. 
recombinants has taken the entire protein from the respiratory parental virus. If the predicted role of the $\mathrm{S}$ protein domain around amino acid 219 in tropism is correct, group 2A recombinants should infect the enteric tract, while those of group $2 \mathrm{~B}$ should be respiratory. The tropism of PUR46-cluster of viruses, as well as group 2A of recombinants was tested. All these viruses could efficiently replicate in lungs. PUR46-SW11 and PUR46 could be isolated in the enteric tract, while PTV-ATT and PTVtsdmar were not, as expected. Recombinants of group 2A were able to infect the small intestine. These results support the hypothesis that the area around position 219 of the S protein, taking in this group from the enteric parental strain, is involved in tropism.

\section{DISCUSSION}

PUR46-cluster of viruses does recombine. The estimated frequency of recombinants isolation $\left(<1.0 \times 10^{-6}\right.$ per $10^{3}$ nucleotides $)$ is lower than that described for murine coronaviruses ${ }^{10}$. Due to this low frequency, selective pressure has to be used to eliminate parental viruses in order to isolate recombinants. The use of selective markers mapping in distal parts of the genome increases the distance to recombine. The markers that were used to select the recombinants (dmar and $t s$ mutations) were located, at least, at $4 \mathrm{~kb}$ from each other. Nevertheless, $40 \%$ of the isolates that were analyzed have recombined within nucleotides 655 and 1756 of the S protein. This concentration of recombinants having the crossing-over in this region could be due either, to a high frequency of recombination in the area, or to a selective advantage of viruses having this genome.

The respiratory PTV-ATT was originated from the enteric PUR46. Sequencing analysis has shown that enteric tropism has been lost in PTV-ATT without changes neither in 3'-UTR nor in the proteins encoded by ORFs 3a, 3b, 4, 6, and 7, when compared to PUR46 strain. Although in this cluster of viruses enteric tropism could be lost without changes in these genes, it does not imply that mutations affecting ORFs 7, 6, 4, 3b, and $3 \mathrm{a}$ could not lead to a change of tropism. In fact, several laboratories have reported data suggesting a possible involvement of ORF3a in TGEV enteropathogenicity ${ }^{9}$ and attenuation.

The tropism of group 2A recombinants strongly suggests that the area around nucleotide 655 of the $\mathrm{S}$ gene is involved in the enteric tropism of this cluster of viruses. To make a definitive statement group $2 \mathrm{~B}$ recombinants has to be further characterized. S protein plays an essential role in the attachment of virions ${ }^{16,14}$ and in the fusion of viral and cellular membranes ${ }^{9}$. Aminopeptidase N (APN) is known to act as a major receptor for TGEV in cell culture ${ }^{4}$. MAbs specific for the antigenic sites $A$ and $D$ are the best inhibitors of virus binding to ST cells, suggesting that the domain recognized by the cellular receptor on ST cells must be located spatially close to these sites ${ }^{16}$. PRCVs, that have a large deletion at the 5 '-end of the $\mathrm{S}$ gene including the area around nucleotide 655 , may also use APN to entry into cells ${ }^{9}$. In fact, binding of APN to both TGEV and PRCVs is mediated by residues located between amino acids $500-800$ of $\mathrm{S}$ protein ${ }^{8}$. All these data indicate that the viruses of this cluster having nucleotide 655 mutated which do not infect the enteric tract still recognize APN. Different mechanisms could be proposed to explain how the area around position 219 of the $\mathrm{S}$ protein is involved in tropism. One possibility is the presence of a second cellular receptor needed for in vivo virus entry into cells of the enteric tract. The receptor binding-site would map around position 219 in the S protein. Another possibility is, as proposed for MHV ${ }^{19}$, the need of a spike protein-dependent cellular factor, other than a virus receptor, required for a productive virus cycle in the enteric tract. The cellular factor would interact with the spike protein in the area around amino acid 219. The analysis of group 2 recombinants will be very helpful to explain the role of S protein in tropism. 


\section{ACKNOWLEDGMENTS}

We are grateful to $M$ Welter and $\mathrm{L}$ Welter (Ambico, Dallas Center, IA) for providing to us the PTV-ATT and the $t s$ mutant derived from it This work has been supported by grants from Consejo Superior de Investigaciones Cientificas, the Comision Interministerial de Ciencia y Tecnologia, Instituto Nacional de Investigaciones Agrarias, La Consejeria de Educacion y Cultura de la Comunidad de Madrid, from Spain, and the European Communities (Projects Science and Biotech) M L Ballesteros received a fellowshıp from Consejo Superior de Investigaciones Cientıficas

\section{REFERENCES}

1 Bohl, E H Antibody in serum, colostrum, and milk of swine after infection or vaccination with transmissible gastroenteritıs virus Infect Immun 1972, 6 289-301

2 Britton, P, Page, K W, Mawditt, K, Pocock, D H Sequence comparison of porcine transmissible gastroenteritis virus (TGEV) with porcine respiratory coronavirus VIIIth International Congress of Virology 1990 IUMS, Berlin pp P6-018

3 Callebaut, P, Correa, I, Pensaert, M, Jimenez, G, Enjuanes, L Antıgenıc differentiation between transmissıble gastroenteritıs virus of swine and a related porcine respiratory coronavirus $\mathrm{J}$ Gen Virol 1988, 69 1725-1730

4 Delmas, B , Gelfi, J , L'Harıdon, R, Vogel, L K, Noren, O, Laude, H Amınopeptıdase N is a major receptor for the enteropathogenic coronavirus TGEV Nature 1992, 357 417-420

5 Fichot, O, Girard, M An improved method for sequencing of RNA templates Nucleic Acids Res 1990, 186162

6 Haelterman, E O, Pensaert, M B Pathogenesis of transmissible gastroenteritis of swine Proc 18th World Vet Congress 1967 Paris Vol 2, pp 569-572

7 Jimenez, G, Correa, I, Melgosa, M P, Bullido, M J, Enjuanes, L Critical epitopes in transmissible gastroenteritıs virus neutralızation J Virol 1986, 60 131-139

8 Laude, H, Godet, M, Bernard, S, Gelfi, J, Duarte, M, Delmas, B Functional domains in the spike protein of transmissible gastroenteritis virus VI International symposium on corona- and related viruses 1994 Quebec, Canada

9 Laude, H, Vanreeth, K, Pensaert, M Porcine respiratory coronavirus - molecular features and virus host interactions Vet Res 1993, 24 125-150

10 Makıno, S, Keck, J G, Stohlman, S A, Laı, M M C High-frequency RNA recombınatıon of murıne coronaviruses J Virol 1986, 57 729-737

11 McClurkın, A W, Norman, J O Studies on transmissıble gastroenteritıs of swine II Selected characteristics of a cytopathogenic virus common to five isolates from transmissible gastroenteritis Can J Comp Vet Sc1 1966, 30 190-198

12 Pensaert, M, Callebaut, P, Vergote, J Isolation of a porcıne respıratory, non-enteric coronavirus related to transmissible gastroenteritis Vet Q 1986, 8 257-260

13 Rasschaert, D , Duarte, M , Laude, H Porcine respiratory coronavirus differs from transmissible gastroenteritıs virus by a few genomic deletions J Gen Virol 1990, 71 2599-2607

14 Sanchez, C M, Gebauer, F, Suñe, C , Mendez, A, Dopazo, J, Enjuanes, L Genetıc evolutıon and tropısm of transmissible gastroenteritıs coronaviruses Virology 1992, 190 92-105

15 Sanchez, C M, Jimenez, G, Laviada, M D , Correa, I, Suñe, C , Bullıdo, M J, Gebauer, F, Smerdou, C, Callebaut, P, Escribano, J M, Enjuanes, L Antigenic homology among coronaviruses related to transmissible gastroenteritis virus Virology 1990, 174 410-417

16 Suñe, C , Jimenez, G, Correa, I, Bullıdo, M J, Gebauer, F, Smerdou, C, Enjuanes, L Mechanısms of transmissible gastroenteritis coronavirus neutralızation Virology 1990, 177 559-569

17 Wesley, R D, Woods, R D, Cheung, A K Genetic analysis of porcine respiratory coronavirus, an attenuated variant of transmissible gastroenteritıs virus $\mathrm{J}$ Virol 1991, 65 3369-3373

18 Wesley, R D, Woods, R D, Hill, H T, Biwer, J D Evidence for a porcine respiratory coronavirus, antigenically similar to transmissible gastroenteritıs virus, in the United States J Vet Diagn Invest 1990, 2 312-317

19 Yokomorı, K, Asanaka, M, Stohlman, S A, Laı, M M C A spıke proteın-dependent cellular factor other than the viral receptor is required for mouse hepatitıs virus entry Virology 1993, 196 45-56 